\title{
'The Sentence Cannot Hold': Language and Legality in Yusuf Atılgan's Anayurt Oteli
}

\author{
By Duygu Ergun*
}

In this paper I will be tracing the concept of sentence in Yusuf Attlgan's Anayurt Oteli written in 1973, one of the most prominent examples of late modernist novels written in Turkish. I aim to primarily look at the rhetorical use of everyday as well as legal language in the narrative that marks the impossibility of agreement between the protagonist Zebercet and his surroundings. Starting with the violent nature of language as means for communication, I will delve into the limits of the expressive capacity of characters in the novel. I also plan to inquire what ethical possibility the narrative might open up to its reader by problematizing the understandability of 'the other.' I will argue that such an ethical concern about 'the other' would, eventually, induce the reader to question the 'binding' nature of the everyday communication that was taken for granted up until modernism.

Keywords: Yusuf Attlgan, Anayurt Oteli, Language, Legal Discourse, Rhetoric, Event, Modernist Literature.

\section{Introduction}

Turning and turning in the widening gyre

The falcon cannot hear the falconer;

Things fall apart; the centre cannot hold;

Mere anarchy is loosed upon the world (Yeats, 1931, p. 346)

William Butler Yeats' poem "The Second Coming" was published in 1920 in the well-known American magazine called The Dial. The speaker in the poem employs a variety of metaphorical expressions to brief its audience about the aftermath of World War I: 'things fall apart,' 'the ceremony of innocence is drowned' and the so-called unifying spirit of the world, a.k.a. 'Spiritus Mundi' now possesses 'a gaze blank and pitiless as the sun.' The catastrophic atmosphere of the post-war Europe is depicted through a description of an expanding, persistent, and 'widening' gyre, whose destructive appearance seems to shatter any hope towards a harmony among people that was presupposed up until modernity. As an outcome of this separating vortex, the image of 'falcon' is irreversibly separated from 'the falconer,' and can no longer hear its owner's call: they have permanently lost track of each other. Overruling the belief in the competency of communication, there can neither be any mediums through which to share or disseminate ideas, nor any common 'spirit,' or consensus of any sort, taking place within this imagined, post-apocalyptic society.

In line with this stream of thought, the idea of the 'second coming,' which is supposed to bring about the eternal unity and mark the salvation of human kind, also becomes hollowed out of any significance. The messianic narrative no longer sets up a comprehensible past through the collectively shared story of Jesus or a preordained

${ }^{*}$ M.A. Student, Boğaziçi University, Turkey. 
future that his anticipated return would launch. In other words, there can be no linear conceptualization of history, and its beginning or end cannot be earmarked. The second coming that is 'hardly' uttered by the speaker in the poem, thus, presents its very incapability of establishing any agreement or order among people as their communicational ground has been and will always fail to function. Hence, the failure and the impossibility of the idea, which problematize the belief in unity after the war, makes the reader doubt and question the accuracy of this shared narrative. Therefore, portraying the revelation of the gyre as the consequence of the war, the poem not only implies the possible disagreements that are likely to take place among people or several states after the World War I; it also demonstrates the constant inadequacy of communication, the impossibility of establishing any agreement with the other party under any circumstances.

Before launching into a discussion on the aesthetic features of language in Yusuf Atılgan's novel Anayurt Oteli (1973), I preferred to start with a poem that expresses disbelief in the power of communication. Considered as one of the most remarkable modernist texts in literary criticism, "The Second Coming" concerns itself with the limits of understanding, when people try to reach an agreement with 'other' members of their society. Similarly, the ethical position of Anayurt Oteli is centered upon the question of relating oneself to the uncompromising 'other:' how could one face or relate to a person with whom one has nothing in common? Is it possible to communicate, knowing the fact that the other party will never be fully understood? Moreover, what triggers this desire to come to terms with 'the other,' and what problems might arise in this process? These are the primary drivers behind the appraisal of how personal relations are depicted in Anayurt Oteli - essentially a story about 'a community of those who have nothing in common' (Lingis, 1994).

The novel tells the story of a young man named Zebercet, who runs a hotel called Anayurt Oteli in a small town of Turkey. We learn that the hotel used to be an old Ottoman residence legated by Zebercet's grandfather. The narrator describes a host of people from different backgrounds, who routinely check in and out of this hotel. While everything proceeds as per usual, Zebercet's life reaches to a turning point one day, when he falls in love with a mysterious woman that checks into the hotel after her train, arriving from Ankara, is delayed. He becomes gradually obsessed with this woman. He starts by preserving her room exactly in the condition that she has left it after she has checked out. Over time, his obsession grows stronger and takes over his daily life. An orderly man of habit, he gives up much of his daily chores such as waking up at six in the morning or shaving steadily three times a week; he shuts down the hotel, walks around the streets aimlessly, attends cockfights in the neighborhood, rapes and strangles the cleaning woman working at the hotel, goes to trials of murder cases as a complete stranger, and in the end, commits suicide.

There seems to be no logical explanation, no chain of causality linking these events to one another in the novel. Berna Moran's (2011) comparative analysis on Yusuf At1lgan's Anayurt Oteli as well as Aylak Adam, another novel by Attlgan (Attlgan, 1959), also emphasizes this anti-deterministic aspect of the narrative. According to Moran, despite the similar themes and character traits, the main distinction between At1lgan's two novels is that Anayurt Oteli never reveals to the reader the exact causes of incidents taking place in the plot (Moran, 2011, p. 293). Indeed, throughout the narrative, the narrator leaves its narratee in the dark: it does not explain the protagonist's rationale behind his actions, which, in an upward spiral of escalating intensity, range from seemingly 'harmless' and obsessive behaviors to the acts of extreme violence such as rape and murder. 
The absence of a link of causality that should weave the narrative together represents the ethical question of the novel: the insufficiency of communication with the other. By disclosing a limited amount of information about Zebercet's experience and thought processes, the language of the narrative constantly maintains a distance between the reader and the protagonist. Atılgan's 'refusal' to render Zebercet more 'understandable' or 'representable' to its readership, at the same time, lays bare its own incapability of telling his experience, as I will discuss more at length below. Furthermore, not only does the narrator fall short of rendering Zebercet's story; it also demonstrates the communicational distance between the socially excluded protagonist and his surroundings. Zebercet's conversations with other characters conceal what they actually think of each other; they employ only a very few words and expressions, the scope of which remains confined to expressions of common courtesy or legal parlance. Therefore, sentences considered from the eighteenth century onwards as the appropriate medium of communication in society (Liftschitz, 2012) 'cannot hold' in Anayurt Oteli. The characters' thoughts and experiences cannot be effectively articulated in everyday conversations in the narrative - which, in turn, makes the reader question the problem concerning the knowledge of the encountered 'other.' How the narrator and characters make use of this 'sentential,' everyday language, and how this underpins the ethical implications of the novel, is the issue I aim to explore in this article.

\section{'Now What Is a Sentence': Violence of the Everyday}

While wandering in town one day, Zebercet decides to watch a traditional cockfight. It turns out to be extremely bloody, wherein the cocks almost kill one another. This, however, does not disturb the audience. The narrator describes this violent scene in an apathetic tone by using short sentences, focusing merely on the succession of events:

Nobody entered the arena. The fight went on. The cock with shorter comb was not running. It fell down while trying to jump; it got up, stumbled. It fell down again when the other cock hits two times with its wings in the last minute; it craned and did not get up. It was lying flat on the ground" (At1lgan, 2014, p. 49). ${ }^{1}$

Although the fight is recounted in immense detail, the narrator describes the subjective experience of pain only in limited terms: the reader gets a sense of how violently the fight is unfolding only through the description of the physical damage one cock has inflicted upon its competitor. However, the narrator remains silent on how much pain the cock must have felt - if any at all. The over-simplicity and mundaneness of this everyday language fails to make the reader sympathize with the other's pain.

Ironically, the language in Anayurt Oteli always foregrounds the violence itself, yet never narrates how it is experienced. It describes the physical reaction the characters show to the pain, but never lets prevail the actual pathos they endure. As in the quotation provided above, while the cock is dying, the narrator relegates its

\footnotetext{
${ }^{1}$ Unless otherwise stated, the text accessed in the Turkish original has been translated by this author for the purpose of this article.
} 
suffering to the sidelines, and instead focuses on reactions of the audience and continues to comment on the fight. Surely, pain is always present in the text; however its effects are not conveyed explicitly. Therefore, the reader can never relate to, or connect with the experience of the characters; in other words, by relaying the events one after another in a mechanized manner, the emotionless language of the novel hinders the reader from identifying with any of the characters. In return, this indifference makes violence unfold, and therefore, in a way, propagates it.

In his introduction to Veena Das' Life and Words: Violence and the Descent into the Ordinary (2007), Stanley Cavell touches upon the issue of believing in the ability to understand the other's pain, stating that it results from the very idea of skepticism in Western thought. He states that the skeptic look realizing its inadequacy to know the other 'results not in a realization of [its] ignorance of the existence of the other, but in [its] denial of that existence, [its] refusal to acknowledge it, [its] psychic annihilation of the other' (p. xiii). The narrator's telling of the ordinary events in a simplistic manner in Anayurt Oteli, therefore, not only hinders the reader from empathizing with the characters' experiences, but also refuses to portray the pain on purpose. By escaping from the other's pain through limiting its existence to the realm of representation, the language serves itself as a testament to violence. Thus, the linguistic expressions of the everyday life are not secure at all; they render the 'unknown' ordinary, and in turn, the ordinary becomes 'hackneyed' (Cavell, 1986). Das also argues that the 'unknowable' pain of the other is, in fact, embedded within these narratives on the ordinary - in the incapability of language that describes the everyday violence (Das, 2007, p. 7). In line with this stream of thought, writing appears here as an ethical question concerning the impossibility of telling about the other's singular, unique experience. Through her reading of Maurice Blanchot's The Writing of the Disaster (1986), Sara Ahmed asserts that the ethical dilemma of writing is constructed through narrating the other's experience without having any knowledge on it. She maintains that writing essentially conveys the weakness of the self that appears 'tormented, vulnerable, and tired' in the process of telling about the unknowable 'other' (Ahmed, 2000, p. 137). Also in Anayurt Oteli, writing is an intrinsically problematic action when the narrator deliberately refrains to give information about the triggering reasons behind Zebercet's behavior. Telling becomes here both a possibility and an impossibility in the sense that the narrator places himself/herself in a troubled position when trying to recount the story with his/her sentences about the untold. Zebercet becomes himself a question of 'the other,' to whom the narrator cannot give its audience any access to his experiences: 'Zebercet: It cannot be said that he is medium height; not short either. According to his military service measures his height is hundred and sixty two centimeters, and his weight is fifty-four' (At1lgan, 1973, p. 12). This act of listing his physical features drawing on a formal document shows the problematic aspect of defining another person according to one's observations. Zebercet will always remain reduced to sentences in the pursuit of representing him accurately. Facing this dilemma of telling in the narrative through the question of representation, the narrator is confronted with an intrinsic problem in the act of writing itself: how to write?

Gertrude Stein, one of the most significant American writers of modernism, discusses the functions of sentences used in writings as well as in everyday conversations in How to Write: '[a] sentence is proper if they have more than they could. They could. Without leaving it. A sentence makes not it told but it hold. A hold is where they put things. Now what is a sentence. A sentence hopes that you are well and happy' (Stein, 1975, p. 29). For Stein, sentences are pleasing because of their reconciliatory meanings. They carry definitive premises, and directly communicate the 
intended message. They, therefore, can provide specific answers to particular questions; by reducing complex thoughts into a 'hold,' they ease the minds of those privy to the conversation. They, therefore, provide a common ground for sharing thoughts and experiences in a society. This very idea of 'hold' is also the reason why Stein criticizes sentences of this sort: they grossly oversimplify, and thus gloss over people's differences by neglecting their unique experiences for the sake of appealing to the so-called collective values of society, and therefore maintaining an easily comprehensible form of "communication." In this way, it becomes a legitimate medium of speech, a sterile contract making things appear as reachable and understandable. A thought and/or experience, it appears, could become understandable, only if the mode of its delivery adheres to the rules of formal logic; in return, what remains as different, obscure or ambiguous for their conventional, everyday speech is left out.

Both Stein's and At1lgan's texts deal with concerns over the use of everyday language problematized primarily in modernist literatures where the conceptualization of 'sentence' is subjected to change. The specific use of language in Attlgan's novel invalidates the everyday language where the sentence, as also implied in Stein's text, becomes an instrument to violate the other's presence rather than serving, as it should, as a medium for agreement among people. The following passage shows one of the rare moments when the reader encounters Zebercet's thinking. The fact that he avoids saying anything until it becomes necessary for him to talk to the man he accidently hits, lays bare the violent power of the everyday conversations on the unique ways Zebercet expresses his thoughts:

'... I had thrown him thus falling out of the attic window into the street in the following morning garbage man must have taken him supposing that he was hit by a car what's his name no name let's call him Karamik isn't he this morning 's police coming now'

(When he turned back suddenly, he hit a man on the arm. 'I beg your pardon' he said.) (Attlgan, 1973, p. 86). ${ }^{2}$

The reader comes into contact with his stream of consciousness until the moment it is ruptured by Zebercet's accidental hit. That he feels obligated to apologize to the main prompts Zebercet to set his genuine thinking aside. Under the conditions imposed by the formal rules of conventional phrases, he becomes unable to express his unique thinking to others. Therefore, the moment Zebercet reacts to the man by saying 'I beg your pardon,' an idiom used for common courtesy, the distance between him and the man becomes absolute: this formal language, invoked in an everyday context, reveals the communicational irreconcilableness between them. Everyday language fails to convey Zebercet's anxiety - which then becomes silenced under the reign of the 'sentential' propriety. Disregarding how Zebercet must have felt at that instance, as he faces the man, the idiom 'I beg your pardon' reduced the unique features of his singular experience to what is acceptable and easily comprehensible.

\footnotetext{
${ }^{1}$ Also etymologically, the word 'sentence' stands for 'opinion,' 'juridical decision' or 'proposition,' (Weekley, 1921, p. 1314) and carries the meaning of 'to pronounce judgment on,' and 'to condemn' (Davidson, 1909, p. 905). Judgment, in these definitions, becomes the precondition of sentence giving definitive meanings to one's actions. In Stein's sense, sentence's capability to reduce one's actions to its own rules, to its own law through judgment, constitutes its violent power.

${ }^{2}$ The translation is by Ezgi Ceylan.
} 
Nurdan Gürbilek's reading of Zebercet's phrase 'I beg your pardon' similarly underlines Zebercet's appearance in the narrative as 'the docile other,' who surrenders to his 'insurmountable destiny of being despised' by people he comes across in his life (Gürbilek, 2013, p. 152). Although he himself is a violent offender who rapes and kills, the violence that is present in everyday life and forms his apathetic and troubled identity, seems to be no less violent than his actions. Zebercet's tragic position, therefore, does not lie in his unusual state of mind; on the contrary, it stems from, and is constructed from the smallest details of his ordinary life: the formal relationships he has to build while running the hotel, the formalities of everyday conversations he has to make with strangers, the right ways to apologize, to show gratitude, or to respond properly. The tragic is then embedded within the very nature of roles one has to adopt when trying to come into contact with others, or basically, to forge ahead with the everyday life. Gürbilek, therefore, argues that 'the main problem in Atılgan's fictions is the existence of other people' (Gürbilek, 2013, p. 160) who perform those roles out of their own volition, in order to impose their authority on others, like the two villagers who break into the hotel and threaten Zebercet to look for the woman's towel with whom Zebercet is in love. One gets the sense that they take for granted the way they do things, and they see no harm in inflicting pain on Zebercet, since they apply the basic, 'conventional rules,' by which they have been raised. In this respect, what is considered 'violent', is determined by the principles of inclusion and exclusion ingrained in the collective unconscious - the norms and traditions people have developed, laws that they have formulated, as well as the 'true' history they believe in.

How then, are the formal and daily uses of 'sentences' invalidated in Anayurt Oteli so that the narrative sets up its ethical stance concerning the impossibility of representing the other within the language? I argued earlier that the daily use of sentences does not foreground the singular experiences of the characters. However, the norms that are followed by the rules of everyday discourse, becomes emptied by the infusion of different uses of language in the narrative, and the idea of unity between the parties of conversation is replaced by the idea of absolute separation and plurality. Emmanuel Levinas also discusses the language's potential to reveal the differences between people and to bring forth the space where they, revealing their different identities, can contest (Levinas, 2011, p. 195). The absolute difference is inconceivable through formal logic, as it cannot be revealed within the conventional and representational boundaries of sentence that 'pleases by its sense.' Anayurt Oteli breaks the authority of sentence by laying bare its limits, by demonstrating the characters' limited recognition of Zeberet as well as the narrator's limited recounting of his experiences. As Ülkü Onart (1978) argues in his narrative and discourse analysis of Anayurt Oteli, the communicative agreements among the characters in the novel is challenged by a variety of narrative techniques, such as the use of third-person narrator focusing on Zebercet's singular perspective, or the use of legal discourse dominating other voices in the narrative. Contesting and limited discourses, perspectives, and uses of language in the narrative imply the irreducible possibility of non-representable identities of characters, despite their obligatory relations with society, with law, or with others in the narrative.

Dealing with the contradictory nature of representation which sets the means as well as the limits of telling about one's story or experience, the language becomes of vital importance concerning the ethical problem of knowing the other in the narrative. The narrator, for instance, deliberately refrains from explaining the reasons behind Zebercet's actions by breaking the claims of any judgment on his behavior. By doing so, the narrator preserves Zebercet's identity without trying to break down any causal relations of his conducts to the narratee. It refuses to become an intermediary who 
appears to know everything about Zebercet. The narrator's position is significant in the sense that it leaves the unknowable parts of Zebercet's identity outside its claim. It never tends to define more than it could by making the obscurity of characters in the story apparent. However, its depictions remain always within the boundaries of its limited knowledge about Zebercet. The following passage, for example, is taken from the part in which Zebercet rapes the cleaning woman; the narrator recounts only what can be observable without adding any judgment to the story it tells:

He approached the bed. Her head was inclined to the left; neck veins were swollen. He put his hand beneath the pillow: she was there. He pulled the quilt up to his tiptoe; up to the bedpost ... He put his hand to her leg, move it to the top; she was warm, his fingers wandered among the hair, he grabbed and pulled. She moved. He lied next to her unbuttoning her shirt; caressed her breasts: plump, firm

(Atılgan, 1973, p. 57).

How Zebercet's actions are described are overly physical: the position and form of the woman's neck, the movements and warmth of her body, and the sensation Zebercet feels in his fingers are depicted in the minutest detail. The narrator does not take a single step beyond the purely descriptive writing of a rape scene. The sentences relay factual information, without any recourse to describing any signs of emotion or moral judgment. One hears the same, cold voice that recounts the story. Since it is impossible to narrate any event in a subjective fashion, the narrator prefers describing in the narrative what is observable and sensible.

Atılgan's limited use of descriptive detail and emphasis on physical aspects of scenes of violence and sexuality, also illuminates the 'ungraspable experience' of the other through a different angle: what can be 'known' about the other lies only in the sensible; in other words, it cannot be known, but sensed - which fixes the real meaning of the idea that is trying to be conveyed within an ambivalent grey zone. which is itself extremely limited for the perceiver. Zebercet's experience is somewhat concealed yet disclosed, known and unknown at the same time. It can never be fully understood by the reader; but at the same time she/he is constantly exposed to its effects. The portrayal of Zebercet's experience, therefore, pushes the conventional understanding of representability through which only his physical reactions to his surroundings are revealed. We, as readers, see his grabbing, pulling, caressing, and his wandering fingers, but never receive a word that describes/represents his experience as a whole. The limited exposure of Zebercet's affective state, therefore, hinders the reader from sympathizing with him. Although the information is given about Zebercet's demeanors, what is knowable about Zebercet's experience is precluded. The language here, then, delineates what is reachable from what is not.

The presentation of Zebercet's contact with the cleaning lady's body agrees with Derrida's argument in his reading of Jean-Luc Nancy regarding the nature of touch in On Touching: Jean-Luc Nancy (2005): he maintains that the experience of coming into contact with the other through touching parallels, in some way, how concept of law distinguishes what is allowed, touchable, contactable or knowable from all that is not (Derrida, 2005, p. 66). Treating the act of touching and the law as concepts that set boundaries, Derrida also implies that the experience of touching leads to an impossible experience where its absolute laws or boundaries can no longer be determined (ibid., p. 111). Yüce Aydoğan's in depth analysis of Anayurt Oteli is also helpful in discussing the issue of touching as a limit-experience (Aydoğan, 2012). He states that the possibility of touching does not seek the activeness of a physical body but the 
passivity of flesh being open to its outer impacts. In addition, he claims that this infinite openness to the impacts of outer space determines the very power in Zebercet's mode of living. His physical responses to his surroundings never set any closure, law, or boundary; but have always already 'transgressed' their possible limits that were socially constructed from the very beginning (Foucault, 1977). As the limit has been overruled from the very beginning, there can be no longer an absolute law to be crossed. This common dilemma and thus, impossible experience of transgression taking place in the act of touching, understanding or telling about the other poses here the ethical concern of the novel about the 'knowability'/reachability of the other. Norms, laws and language set by the society Zebercet lives in, therefore, preclude his openness to experience that is inherently lawless; and at the same time, the conventional language instrumentalized by the narrator for telling Zebercet's story is violating his presence by setting reductionist boundaries to his experience. There are, therefore, two layers of ethical stalemate concerning the position of the 'other' in Anayurt Oteli, one of which is revealed in the story itself, and the other lies in the way the story is told.

Through the way Zebercet's story is told, we, as readers, confront the limits of knowing him: what is knowable in his life is determined by the laws of representation in language. Language, here, serves as the law that determines what could be told. The position of the narrator in Anayurt Oteli, thus, problematizes the unity of stories that are narrated to an assumed addressee in a comprehensive way. It problematizes the conventional language to narrate the language that is expected to be rhetorical, in the constant strive to make the story complete, coherent and persuasive to its audience.

Indicating the problematic characteristic of the rhetorical aspect of language in Anayurt Oteli that violates Zebercet's way of being while recounting, the narrator tends to redefine his role by avoiding to tell the story of him on behalf of him in the narrative. However, the communicative medium from which the narrator tries to avoid this, also proceeds from the everyday conversations taking place between characters in the narrative. How, then, is the narrative able to overcome the violating characteristic of the everyday language? And especially, how can it escape the law of language that usually puts the conversation to a closure through definitive judgments?

\section{Law and Responsiveness: Undoing the Space of Rhetoric}

As I have indicated in the previous section, the ethical problem of the language concerning the representability of the other's existence, not only lies in the narrator's discourse, but also prevails in the language used by Zebercet and his surroundings. In this section, therefore, I will focus more on how the idiosyncratic speeches of characters undo the premise of communication in the everyday use of language in the narrative.

Zebercet's long and inner monologues provide the reader with examples of how the communicational aspect of language is overruled by Zebercet's grammar-free, irreconcilable and fragmented expressions. The excerpt below, considered as one of the most remarkable, 'striking, bloody, complex and at the same time one of the most poetical imaginary revenge scenes in Turkish literature' (Gürbilek, 2013, p. 151) is a striking case in point. It presents Zebercet's furious but silent reply to the insult of a roasted chestnut seller, who scolded him by saying 'Why are you standing there like a lemon? Buzz off!' (At1lgan, 2014, p. 83): 
A handful of sand might be thrown to the chestnuts we take the sand from Pig River / you look like a pig / a donkey / an ox / a cow / a mule / a monkey / a bear / a hippopotamus / a cockroach / a rat / a dog / a coyote / he strangled the coyote by jumping on it said his uncle he said I won't let my mare be eaten would he strangle it if they let him would it be ever known would he be scared of facing the end ... (ibid., p. 85)

Zebercet's thinking process does not convey a direct message for the other party to understand. It is a convoluted response that clearly does not seek a reaction; a unique way of employing the language, which brings to the fore Zebercet's personal memories, such as the day his uncle tries to strangle a coyote. The singular characteristic of his language underlines the singularity of his experience, and alludes to the fact that any shared, cultural and communicative medium between the seller and himself would eventually fail. In this scene, Zebercet remains particularly silent; his expressions do not comply with the rules of propriety, and his sentences are not constructed in a way that effortlessly articulates the intended meaning. His words, therefore, stand for his unique existence - for his particular history, language, and identity, which cannot be reduced to any form of common parlance.

The uniqueness of Zebercet's expressions impresses upon the reader to reevaluate and question the promises of communication during the process of reading as well. Unlike carrying a rhetorical end that would eventually instruct its reader, Anayurt Oteli places an ethical question around the act of reading itself, and suggests alternative ways of 'coming into contact' with others. Before delving into this particular issue, in this section I continue discussing the ethical position taken by the novel through its particular uses of language. I will touch upon the problem of rhetoric in the narrative, which causes the novel to take such a position in the first place.

According to Aristotle, rhetoric is the art of persuasion through language that is designed to have impact on a specific audience (Aristotle, n.d.; Cascardi, 2004, p. 307). As the purpose of rhetoric is to impress the other party during a conversation, it brings about the use of particular techniques directing the addressee to agree on the plausibleness of the proposed argument. Extracting an affirmative response from the audience, therefore, becomes the primary objective of the speech. In this sense, the conversation is one-sided; the rhetorician is not interested in getting to know about the person/people he addresses. Stating '[n]ot every discourse is a relation with exteriority,' Levinas (2011, p. 70) emphasizes in his ethical theory that in the rhetorical use of language, a genuine, metaphysical desire of self being open and nonjudgmental to the other's differences, is lacking. On the contrary, rhetoric, he argues, sets a barrier with the other, withholding one from giving any effort toward recognizing the unique presence of the other party:

Rhetoric, absent from no discourse, and which philosophical discourse seeks to overcome, resists discourse (or leads to it: pedagogy, demagogy, psychagogy). It approaches the other not to face him, but obliquely - not, to be sure, as a thing, since rhetoric remains conversation, and across all its artifices goes unto the Other, solicits his yes. But the specific nature of rhetoric (of propaganda, flattery, diplomacy, etc.) consists in corrupting this freedom. It is for this that it is preeminently violence, that is, injustice. (ibid.) 
Levinas argues that rhetoric operates within a kind of speech that is different from a veritable conversation where the other's singular, unique experience or presence can be faced. Focusing strictly on soliciting 'yes' from the other, the nature of the rhetoric does not extend to the interlocutors the possibility of sharing anything subjective. In other words, rhetorical language corrupts and violates the other's freedom by reducing its experience to representable, plausible arguments that are appropriate to its limited conversational arena. Therefore, it erases their personal differences and does away with the possibility of engaging in a genuine, veritable conversation. Under such conditions, as Levinas mentions, justice can only prevail by 'overcoming of rhetoric' where the other can be, though limitedly, accessed in its own presence.

By problematizing and nullifying the rules and means of the everyday conversation as in the example I have given above, therefore, Zebercet's idiosyncratic use of language empties the communicative premise of rhetoric in his setting. His everyday environment becomes entirely a field for violence, as the law that governs everyday life categorizes its subjectivities into well-defined groups, and does not recognize anyone, who abides by its decrees, as anything else than a 'citizen.' Sentences or judgments, therefore, function within the rhetorical framework of both legal discourse and everyday language, where the subjects can be thought as 'knowable,' and the daily communication can proceed comprehensively.

One of the most remarkable examples for the problematization of legal discourse in Anayurt Oteli can be given from Zebercet's attendance in trials. During his continuous visits to the courthouse in order to follow a specific murder case, Zebercet pretends to answer the questions in his mind as if the questions are directed to his own killing of the cleaning woman:

- Doctor said she was truly a virgin. Her father told that he had not even let a male fly perch on the girl. Why did you kill her?

'His father you said his father had already died then they sent her back because she was already touched, she was naked on the bed in the small hours her eyes, mouth opened I pulled the quilt over her...'

(At1lgan, 1973, pp. 74-75) ${ }^{1}$

The question of 'why' here indicates the determination of the judge to elicit a direct response from the accused. The appropriate answer to the question 'Why did you kill her?' is normally expected to solve the case, and lead to a tribunal to a discussion on what kind of punishment the person deserves in accordance with his motive for murder. Any plausible reason would make sense within the socially agreed rules of such conversation, as any answer would remain within its legitimate boundaries. This question seeks a straight-forward answer, and does not concern itself with finding out the singular, subjective experience of Zebercet as the other.

Zebercet's reaction in response to this very question is not the answer one anticipates; it does not really engage with the question, nor does it reveal the motive behind the act of killing. Rather, his answer reveals his unique existence as the 'other': instead of confirming with the rules of legal discourse, and thus delivering a statement that clearly answers the question, Zebercet's response contains many grammatical errors. By formulating his sentences in an unconventional way, he also refuses to act in accordance with the communally-accepted laws of conversation. Through his language, therefore, Zebercet cannot be recognized as a mere 'criminal'

\footnotetext{
${ }^{1}$ The translation is by Ezgi Ceylan.
} 
and cannot be reduced to a representable, knowable subject 'in front of the law'; he delineates an inevitable gap between his unreachable, unexplainable presence and the legal formalities that constantly try to define him as an accused subject.

By analyzing Kafka's parable 'Before the Law' (1978), Derrida mentions the similarity between the impossibility of the idea of an absolute law and storytelling: 'narrative accounts would try to approach the law and make it present, to enter into a relation with it, indeed, to enter it and become intrinsic to it' (Derrida, 1992, p. 191) but in the end, it becomes an impossible act as every story is singular and irreducible to language's representativeness. Derrida argues that the story as well as its title 'before the law' presupposes a shared unity and meaning; however, it can never surpass being merely 'a title,' (ibid., p. 188) being a fake indication hiding the singularity of the story that is told. Let us recall the defendant's recounting of the murder case in Anayurt Oteli where telling becomes impossible 'before the law':

$\ldots$ in a while she shrilled I ran the door was open Fatma Kuruca collapsed while crying the bride was lying on the bed inside naked her face been crushed she was in blood her hair dispersed on the pillow her chest was also bloody it was asked he said there was nothing in her hands it was asked he said that he did not see the pitcher ... (Atılgan, 2014, p. 72)

The revelation of the story's singular, non-representable, and irreducible violence is told in a machinated tone desensitizing the potential effects of the narrative on its audience. The dead bride, lying on the bed in blood, is similar to the defeated cock lying on the ground at the end of the fight whose experience is impossible to be told. They are the voiceless others being present in these violent scenes. They are voiceless, yet present: their existence cannot be ignored, though impossible to be reached, known, or understood. The story told in the courthouse to the typist hides what was really endured when the event took place, and the actual pain is lost forever. Before the law, events are told in full detail where their singularities are kept out.

The singularity of a story, however, is both contained and hidden within its insufficient language. It can never be told, but it cannot be neglected either. The story, whose law lies in its sentences, delineates both the possibility and impossibility of telling about the singular experiences. Through its insufficient language, therefore, Anayurt Oteli both enables and disables the reader's access to the story of Zebercet and other characters: It makes them appear, but at the same time it reduces their presence to limited representations. What might the novel, then, ask its reader about her/his limited understanding of the characters during the reading experience? What possibilities could this ethical question about the representability of the other, bring the reader? In the following section, I will shortly touch upon the ethical stance of Anayurt Oteli by focusing on its aesthetic potential of moving its reader.

\section{Ethical at the Outset: The Primacy of the Event}

As I indicated at the beginning, the narrator of Anayurt Oteli never reveals to its reader the determining causes of the events. The narrative tells the successive events in short, and informative sentences, and it eliminates any connection to the prior happenings in the story. As 'The Second Coming,' I argued that Anayurt Oteli breaks the promise of a telos; an ultimate, binding purpose of the universe or a story that 
would constitute a whole. Events in the narrative appear as separated from each other as taking place in a chaos where they have no beginning or end. The narrator describes them as if they only occur as coincidences; they are not portrayed as a result of another event, and therefore, they can only appear in their singularity. Similar to the portrayal of characters as 'singular' others, the depiction of the events also appear in the narrative as unique cases, which cannot be reduced to a rational chain of causality.

Troubling the rational logic, the events told in the narrative, therefore, empty any kind of expectation in the reading process as well. Random incidents appearing in the course of the narrative do not allow the reader to 'know,' 'understand,' or even 'speculate' about what is going on; the events remain unreachable. The following scene where Zebercet finds himself on the edge of an accident can illustrate this randomness that, in turn, will contribute to the novel's ethical position, as I will explain later:

He trembled as he traversed with the packages in his hand. The car has stopped just a bit further. The driver greeted with his head, smiling. $\mathrm{He}$ smiled back; he said 'I'm sorry.' People passing by also were smiling. He walked quickly. It was a sweet accident; but how easy it was for one to die. (At1lgan, 2014, pp. 22-23)

The scene invalidates any possible scenario relevant to the course of events in the plot. The accident comes to happen in an instant, without showing any 'tangible' causes, as Catherine Malabou argues in The Ontology of Accident (2012). Zebercet, the driver and people in their surroundings all smile, while confronting this unexpected happening. Their smiles indicate that they are in some way disturbed facing this uncontrollability, and relieved by its instantaneous delay. This constant potential for disaster in the narrative, demonstrates to the reader its insufficiency to anticipate, or know.

The same pattern in the reading experience repeats itself when it comes to characters. For example, as an 'unexpected' and 'untimely' baby, Zebercet's coming into the world is considered by his parents and neighbors as an accident. Or we, as readers, for instance, are never informed when he decides to commit suicide; he continues on doing his everyday habits: he gets up and dresses, makes the bed, washes his face, and drinks tea before hanging himself (Atılgan, 2014, p. 105). The demeanors of characters, such as the events, do not pertain to a hierarchical order in terms of their assumed 'significance.' Every character appears in the novel, therefore, as a potential, as a contingency; their actions are never presented by particular reasons explaining their behaviors to some audience as a whole. They are singular and equally present in their unique beings, and this constant lack of information about them leads the reader to question its adequacy to know the other person.

By exposing the ethical problem in the understandability of the other, the novel invites the reader to think further about their own relationships with their surroundings. In line with the premise of the novel, as Derrida (1992) and others (Blanchot, 1989; Altieri, 2003; Attridge, 2004; Clark, 2005) argue, literature becomes a singular event that uniquely affects its reader to take ethical actions. It has a power to establish a subjective effect on the side of its reader through its aesthetic impact resulting from the particular uses of language. As I have argued before, just like the portrayal of events and characters, the act of telling in Anayurt Oteli harbors a potential: it both hides and reveals parts of events or experiences, with which the reader can never fully come into contact. The limited visibility of the other prevails 
only from the distance the narrator maintains. Telling, therefore, becomes an essential part of the ethical concern portrayed through the use of language in the novel. One of the most remarkable examples of the distancing language of the narrator can be given from the part where Zebercet meets Ekrem, the seventeen-year-old boy with whom he engages for the first time a homoerotic experience in the movies:

He pulled out his cigarette box and asked. He doesn't smoke. He asked. His name was Ekrem. He lighted his cigarette upon his asking. 'Ahmet' he replied. He asked. He came from the village last year, he used to work at an ironsmith's shop at the industrial bazaar of the town. His wage was low; yet he was learning the craft. He asked. He is staying with his old, lonely aunt. ... He was on his right side; his arm touches him they settled. The boy said: 'This cinema is the best one.' He has some hair faintly visible on his upper lip, around the beard line on his cheeks. He asked. He recently turned seventeen.

(At1lgan, 2014, pp. 50-51) ${ }^{1}$

The narrator focuses here merely on the actions and statements of Zebercet, introducing himself as 'Ahmet,' and that of the young boy Ekrem. The conversation is rendered in such a way that it displays the difference between what they experience and what they say. The words they use never reflect their intense attraction; they continue to speak on an 'agreeable' ground that would remain appropriate for their surroundings such as asking about each other's name, age, what they do, where they come from, or just making comments like 'this cinema is the best one.' The questions they pose to each other are presumable and expected - they are insignificant compared to their actual experience of sexual attraction, therefore the narrator reduces their questions to the same phrase 'he asked,' without giving their contents.

Their verbal distance, however, is crossed rather through a bodily language, which could not be expressed by the rules of their formal communication. After the conversation I quoted above, only some hints of their experience, though limited, could be seized from the descriptions of their movements: the touch of their arms and knees, the feeling of warmth in each other's hands, Zebercet's erection and the boy's instant snuggling during the film they watch is described in detail (Atılgan, 1973, p. 51). The gap between their genuine attractions and formal statements along with the limited presentation of their affects to the reader entails the language's inadequacy to express or tell about the other's experiences. Thus, by telling only about the said and the performed, the narrator puts the characters into an unknown position for the reader, and lets the reader question his/her own encounter with others both in fiction, and in their everyday lives.

In conclusion, the rules of everyday language in Anayurt Oteli are transgressed, and then nullified by the alternative uses of language. Especially the protagonist Zebercet's alienation from his surroundings through his miscommunication with other characters, brings about his otherness, leading to his singular presence in the novel from the very beginning. His presence creates a contradiction with the language of the law making decisions about punishments, deliberately neglecting his and the other's existence by reducing them to its own rules. The everyday language is no different from the legal one: it violates the other's singular identity for the sake of establishing a communicative agreement.

\footnotetext{
${ }^{1}$ The translation is by Ezgi Ceylan.
} 
The sentence and its definitive judgments cannot hold in Anayurt Oteli because of the possibility that is opened up by the expression of unique experiences of the 'other' in the language. The language violates the narrative from the beginning that undoes the assumed unity and certainty of communication. By undoing the premises of definitive sentences, Anayurt Oteli proposes to its reader an alternative way of approaching others without judging them. The narrative ethically questions the very idea of claiming to know about the other, and lays bare the everyday violence, taking place within the communication itself.

\section{References}

Ahmed, S., 2000. Strange Encounters: Embodied Others in Post-coloniality. London $\&$ New York: Routledge.

Altieri, C., 2003. The Particulars of Rupture: an Aesthetics of the Affects. Ithaca: Cornell University Press.

Aristotle, n.d. Rhetoric. Translated by W.R. Roberts. In: Internet Classics Archive. Available from: http://classics.mit.edu/Aristotle/rhetoric.mb.txt [Accessed June 05, 2015].

Atılgan, Y., 1959. Aylak Adam. Istanbul: Varlık Publishing.

Atılgan, Y., 1973. Anayurt Oteli. Ankara: Bilgi Publishing.

Atılgan, Y., 2014. Anayurt Oteli. Istanbul: Yap1 Kredi Publishing.

Attridge, D., 2004. J. M. Coetzee \& the Ethics of Reading: Literature in the Event. Chicago: The University of Chicago Press.

Aydoğan, Y., 2012. Aşk Ve Profanlaşma: Bir Anayurt Oteli Konaklaması. In: Modern Turkish Literature Symposia II: Yusuf Attlgan. Kadir Has University, November 11, 2012, Turkey.

Blanchot, M., 1986. The Writing of the Disaster. Translated by A. Smock. Lincoln: University of Nebraska Press.

Blanchot, M., 1989. The Space of Literature. Translated by A. Smock. Lincoln: University of Nebraska Press.

Cascardi, A.J., 2004. Arts of Persuasion and Judgment: Rhetoric and Aesthetics. In: W. Jost \& W. Olmsted, eds. A Companion to Rhetoric and Rhetorical Criticism. Oxford: Blackwell Publishing Ltd., pp. 294-308.

Cavell, S., 1986. The Uncanniness of the Ordinary [pdf]. In: The Tanner Lectures on Human Values, Delivered April 3 and 8. Stanford University. Available from: http://tannerlectures.utah.edu/_documents/a-to-z/c/cavell88.pdf [Accessed June 6, 2015.

Clark, T., 2005. The Poetics of Singularity: the Counter-Culturalist Turn in Heidegger, Derrida, Blanchot and the Later Gadamer. Edinburgh: Edinburgh University Press.

Das, V., 2007. Life and Words: Violence and the Descent into the Ordinary. Los Angeles: University of California Press.

Davidson, T., 1909. Chamber's English Dictionary: Pronouncing, Explanatory, Etymological. London: W. \& R. Chambers Ltd.

Derrida, J., 1992. Acts of Literature. D. Attridge, ed. New York: Routledge.

Derrida, J., 2005. On Touching: Jean-Luc Nancy. Translated by C. Irizarry. Stanford: Stanford University Press.

Foucault, M., 1977. A Preface to Transgression. In: D.F. Bouchard, ed. Language, Counter-Memory, Practice: Selected Essays and Interviews. Translated by D.F. Bouchard \& S Simon. Ithaca: Cornell University Press, pp. 29-52. 
Gürbilek, N., 2013. Yeraltında Neler Var? In: Mă̆durun Dili. Istanbul: Metis Publishing.

Kafka, F., 1978. Before the Law. In: Wedding Preparations in the Country and Other Stories. Translated by W. \& E. Muir. Harmondsworth: Penguin.

Levinas, E., 2011. Totality and Infinity: an Essay on Exteriority. Translated by A. Lingis. Pittsburgh: Duquesne University Press.

Liftschitz, A., 2012. Language and Enlightenment. Oxford: Oxford Historical Monographs.

Lingis, A., 1994. The Community of Those Who Have Nothing in Common. Bloomington: Indiana University Press.

Malabou, C., 2012. The Ontology of the Accident: an Essay on Destructive Plasticity. Translated by C. Shread. Cambridge: Polity Press.

Moran, B., 2011. Aylak Adam'dan Anayurt Oteli'ne', Türk romanına eleștirel bir bakış 2: Sabahattin Ali'den Yusuf Atılgan'a. Istanbul: Iletişim Publishing, pp. 291-314.

Onart, Ü., 1978. Bir Iletişim Çıkmazı: Zebercet. In: T. Yüksel, et al., eds. Yusuf Atılgan'a Armağan. Istanbul: Iletişim Publishing, pp. 239-262.

Stein, G., 1975. How to Write. Dover Publications.

Weekley, E., 1921. An Etymological Dictionary of Modern English. London: John Murray.

Yeats, W.B., 1931. Later Poems. 5th ed. T. Ballylee, ed. London: MacMillan \& Co. Ltd. 
